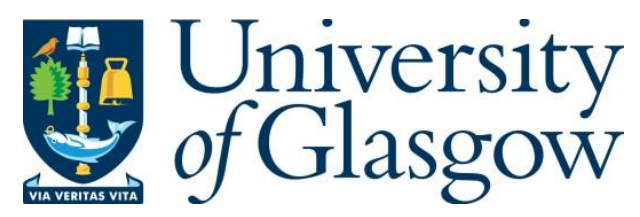

Galbraith, L., Leung, H. Y. and Ahmad, I. (2018) Lipid pathway deregulation in advanced prostate cancer. Pharmacological Research, 131, pp. 177-184.

(doi:10.1016/j.phrs.2018.02.022)

There may be differences between this version and the published version. You are advised to consult the publisher's version if you wish to cite from it.

http://eprints.gla.ac.uk/158338/

Deposited on: 24 April 2018

Enlighten - Research publications by members of the University of Glasgow http://eprints.gla.ac.uk 


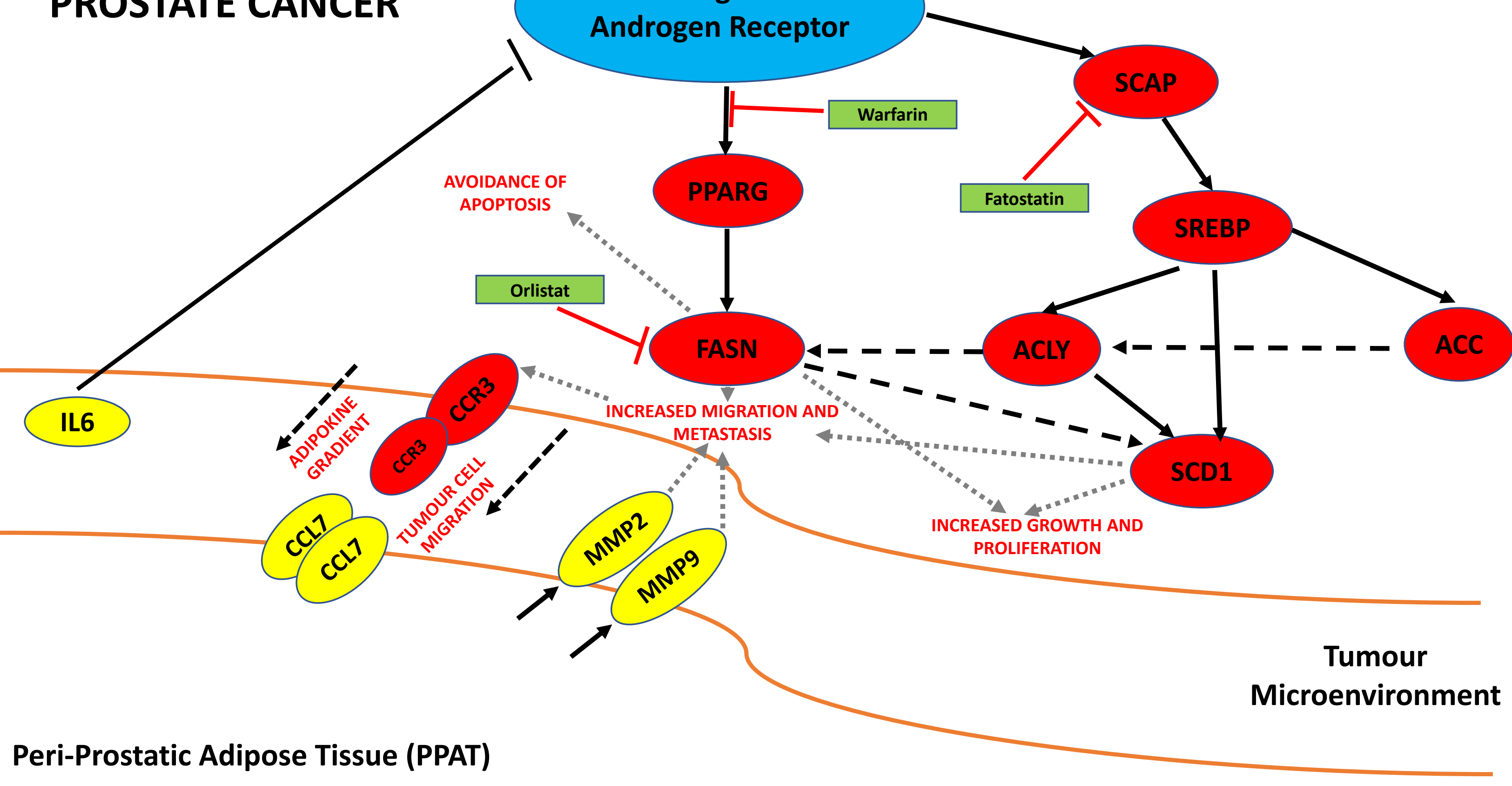




\section{Lipid Pathway Deregulation in Advanced Prostate Cancer}

Laura Galbraith ${ }^{1,2}$, Hing Y Leung ${ }^{1,2}$, Imran Ahmad ${ }^{1,2, \#}$

${ }^{1}$ CRUK Beatson Institute, Garscube Estate, Switchback Road, Bearsden, Glasgow

G61 1BD, UK.

${ }^{2}$ Institute of Cancer Sciences, University of Glasgow, Glasgow G61 1QH, UK.

Correspondence:

\#Imran Ahmad, Email; imran.ahmad@glasgow.ac.uk

Running title: Lipids in PC

Word Count: Manuscript - 4987

Keywords: Lipid, Metabolism, Prostate Cancer

Conflict of Interest: All authors state that there is no conflict of interest 


\section{Abstract}

The link between prostate cancer (PC) development and lipid metabolism is well established, with AR intimately involved in a number of lipogenic processes involving SREBP1, PPARG, FASN, ACC, ACLY and SCD1. Recently, there is growing evidence implicating the role of obesity and peri-prostatic adipose tissue (PPAT) in PC aggressiveness and related mortality, suggesting the importance of lipid pathways in both localised and disseminated disease. A number of promising agents are in development to target the lipogenic axis in PC, and the likelihood is that these agents will form part of combination drug strategies, with targeting of multiple metabolic pathways (e.g. FASN and CPT1), or in combination with AR pathway inhibitors (SCD1 and AR). 


\section{$\underline{\text { Introduction }}$}

Prostate cancer (PC) is the commonest adult male cancer in the developed world, and the second leading cause of cancer related death in men (1). The majority of patients are likely to die with, rather than from PC, making it important to identify key pathways that confer poor prognosis, thus minimising overtreatment.

Huggins et alin 1941 demonstrated that PC epithelial growth and survival was dependent upon androgens (2). Androgen deprivation therapy (or ADT) is often the first line treatment in patients with advanced disease. This is achieved via drug treatments designed to block androgen activity, either by direct suppression of the Luteinising Hormone Releasing Hormone (LHRH) or Androgen Receptor (AR) axis, thus, mimicking surgical castration. With time, PC develops resistance to these treatments and the disease progresses to CRPC (castrate resistant PC) form, which is uniformly fatal (3). Thus, a need exists to identify other signalling pathways in PC development and progression, and design specific treatments that exploit the dependencies and vulnerabilities of CRPC.

In 1953 Medes and colleagues (4) observed a relationship between lipid metabolism and cancer. They demonstrated that cancer tissues could generate fatty acids (FAs) and phospholipids through cellular de novo lipogenesis, and were not solely reliant upon lipid/FA uptake from the environment. This is turn provided the support required for the excessive growth and proliferation, which is a hallmark of cancer. The use of FAs in the cell can be utilised for the 
generation of energy via their breakdown by $\beta$-oxidation to generate ATP. The energy demands within cancer cells are much higher than that for non-cancerous cells, at least in part to support uncensored growth and proliferation. However, the use of FAs to synthesise lipids is of equal importance. Membrane synthesis, which is a pre-requisite of growth and cell division, is linked to G1 phase of cell cycle (5). In G1 phase, cell cycle arrest results from suppressed expression of key lipid metabolism genes such as Fatty Acid Synthase (FASN) and Acetyl-CoA Carboxylase (ACC) (6). Besides membrane synthesis, lipogenesis is necessary for other functions (7). For instance, de novo synthesis of mono-unsaturated and saturated lipids plays key roles in signal transduction, intracellular trafficking, cell polarisation and migration (8-10). Each of these processes are often hijacked and deregulated in cancer cells to promote their survival. As such it is not unreasonable to think that disruption or blocking of the lipid metabolism pathways would be detrimental to tumour cell growth, proliferation and ultimately survival, thus representing potential therapeutic targets.

Whilst androgens have long been established as a key player in PC, it has also been observed that advanced prostate tumours accumulate lipid droplets (11). It is now recognised that androgens may play a role in this due to effects they have on lipid metabolism $(11,12)$. Androgens regulate the mRNA and protein expression of one of the key regulators of lipid metabolism, the sterol regulatory element-binding protein (SREBP). SREBPs not only increase lipid metabolism, but also increase cholesterol metabolism (13), which in turn can aid androgen synthesis. It has also been observed that as well as utilising FA's for de novo lipogenesis, PC cells tend to use fatty acids over glucose as an energetic substrate 
through increased $\beta$-oxidation and this is not the case in non-tumorigenic cell lines (14), making lipid metabolism an attractive as well as specific avenue for treatment.

$\underline{\text { Key Regulators of Lipid Metabolism in PC }}$

Sterol Regulatory Element-Binding Protein 1 (SREBP1)

SREBP1 is a master regulator in FA metabolism. It controls the transcription of ATP Citrate Lyase (ACYL), ACC, Stearoyl-CoA Desaturase 1 (SCD1) and FASN. Un-regulated SREBP activation has been linked to obesity, fatty liver disease, insulin resistance, autoimmune diseases, as well as cancer development (15). It is frequently overexpressed in many cancers and is highly associated with increased tumorgenicity and invasion.

As previously mentioned, in PC androgens increase the activity of SREBP (13). This has recently been attributed to androgen receptor (AR) mediated transcription of SREBP-cleavage activating protein (SCAP). SCAP binds to SREBP, and a complex translocates from the endoplasmic reticulum (ER) to the Golgi apparatus, where the complex is cleaved by the proteases SP1\&2, thus releasing SREBP from SCAP, with the N-terminal DNA binding and transcriptional activation domains of SREBP exposed for transcriptional functions on its target genes $(16,17)$. This situation is further compounded by the ability of SREBP, once activated, to further enhance AR expression through binding to a SRE (sterol regulatory element) present in the AR gene (18). SREBP has also been identified as an oxygen sensor in yeast (19). The SREBP pathway can monitor oxygen-dependent sterol synthesis as a measure of oxygen 
availability, and control a transcriptional program required for adaptation to hypoxia, which is frequently found in solid tumours such as those of the prostate.

In addition to response to oxygen and androgens levels, SREBP is also activated by the AKT/PI3K pathway $(20,21)$. AKT signalling in a PTEN null environment (a situation common in PC with PTEN loss being a driver mutation in the disease) increases SREBP expression which in turn up-regulates expression of the Low-density Lipoprotein (LDL) receptor, thus increasing the uptake of particles, containing cholesteryl esters (CE). Depletion of this CE storage led to an impairment in PC aggressiveness, has been observed to attenuate cell growth, both in vitro and in vivo through limitation of the uptake of essential fatty acids (11).

In summary, SREBP is crucial factor in PC progression and interference with its associated pathways in PC may be a possible avenue for treatment of advanced disease. Physiologic inhibitory mechanisms already exist within the cell to prevent over-activation of SREBP. AMPK can phosphorylate SREBP, which prevents the proteolytic action of SP1 and SP2 in the Golgi apparatus, thus preventing SREBP1 activation (22). Another negative regulator of SREBP is Farnesoid X receptor (FXR). Upon its activation through ligand binding of Chenodexycholic acid (CDCA), FXR reduces the mRNA and proteins levels of SREBP, which in turn attenuates SREBP controlled lipid metabolism and consequently reduces tumour growth and proliferation (23). It has been observed that FXR inhibits co-activator recruitment to the SREBP promoter thereby reducing its expression and consequently affecting various downstream 
effectors (24). Interestingly, FXR may also further impact on PC via upregulation of PTEN (25).

Regardless, as a master regulator of lipid metabolism it has been shown that by attenuating its function tumour growth and proliferation are diminished and thus it remains as an attractive drug target.

\section{Peroxisome proliferator-activated receptor gamma (PPARG)}

PPARG is a transcription factor belonging to the nuclear hormone receptor superfamily. It is known to have roles in adipocyte differentiation, lipid metabolism, peripheral glucose utilisation and inflammatory response. It has two isoforms PPARG1 and PPARG2. PPARG1 is expressed in most tissues whilst PPARG2 is present in adipocytes. Previous studies have demonstrated its role as a tumour suppressor in a variety of cancers, showing that upon treatment with PPARG agonists that proliferation of tumour cells is reduced (26-30). It was also thought to be the case in PC (31), however our work (32) and that of others (33) has challenged this view.

In our forward genetic screen using a murine transgenic mouse prostate cancer model driven by Pten deletion (32), PPARG was found to promote metastatic PC by associated up-regulation of the lipid metabolism pathways, more specifically those involved in de novo lipogenesis. Additionally, inhibition of PPARG supressed tumour growth and down-regulated the lipid synthesis pathway genes. PPARG levels were observed to correlate strongly with that of FASN, a key enzyme in the lipid synthesis pathway, and that high PPARG/FASN levels along with PTEN loss conferred poor prognosis. This finding could be used 
therapeutically to stratify patients, identifying those with more aggressive disease who would benefit from a PPARG/FASN derived treatment program. Furthermore, our work as well as that of others suggests that PPARG does not affect the initiation of the primary tumour (34), at least in the mouse models examined, but has a role more specific to the development of aggressive metastatic disease (32). In a separate study, a link was also established between PPARG and PC progression, identifying Fatty acid binding protein 5 (FABP5) as a potential agonist for PPARG, with increasing FABP5 and PPARG levels correlating with disease severity (35). This is in line with earlier work where FABP5 was found to be positively associated with an invasive more aggressive phenotype, which could be abrogated by addition of PPARG inhibitor GW9662, leading the authors to surmise that the metastatic effects they observed through FABP5 over-expression resulted from an FABP5 delivery of fatty acid ligand to nuclear membrane bound PPARG resulting in its activation (36).

A further study also made the prostate specific observation regarding the role of PPARG as an oncogene (33) Whilst attempting to elucidate the mechanism of long-term warfarin (a vitamin $\mathrm{K}$ antagonist) and its role in reducing the risk of PC, they established a functional link between warfarin, AR and PPARG function. Their study demonstrated that warfarin could inhibit AR transcriptional activity, independent of its $\gamma$-carboxylation, through inhibition of PPARG signalling. This suggests that PPARG can act as a regulator of AR, with its inhibition causing reduction in PC growth and proliferation via AR. However, the authors were not able to demonstrate a direct effect of AR on PPARG. This is at odds with another recent study that demonstrates that AR can regulate the activity of PPARG, 
showing that AR normally functions to supress PPARG expression within AR positive PC cells (37). These conflicting observations may simply be because of context and cell line differences, but highlight the need for further investigation into the intersecting regulatory pathways of PPARG and AR, as any potential therapy designed around these axes may lead to a worsening of the disease rather alleviating it. Indeed, it may be that a two-pronged approach is required, targeting both AR and PPARG simultaneously.

As PPARG has been a therapeutic target in disease areas other than cancer, there are already agents available in the clinic known to target PPARG.

Thiazolidinediones (TZDs) or 'glitazones' are agonists of PPARG used in the treatment of type 2 diabetes, through improvements of insulin sensitivity (38). However, the concentration at which the TZDs are used to treat diabetes are far higher than the concentration required for full PPARG activation and thus the mechanism may in fact be due to a PPARG independent effect $(39,40)$. Given the link between diabetes and obesity, and the emerging evidence of the role of obesity and PC (to be discussed later) it is worth re-considering the potential risks of using a drug known to activate PPARG in (these obese and diabetic) men. PPARG represents an exciting new target for cancer therapy, but further investigation is needed to identify the subgroup of patients who would benefit from this targeted treatment.

\section{$\underline{\text { Fatty acid synthase (FASN) }}$}

FASN) is a key component of the lipid synthesis pathway and has been implicated in many cancers $(41,42)$. FAs are essential constituents of membrane 
lipids, and are an essential substrate for energy metabolism. There are two sources of FAs for animal metabolism, namely exogenous (dietary) FAs and endogenous (FASN synthesised) FAs. FASN synthesises long-chain FAs from acetyl-CoA and malonyl-CoA, producing the 16C FA, palmitate (42). In healthy individuals, FASN has minimal effect since there is adequate levels of FA available from dietary fat. Thus, most normal cells will preferentially utilise circulating FA for the synthesis of new structural lipids. In normal conditions, FASN converts excess carbohydrate into FAs, which are then esterified to triacylglycerols that can be stored (and if needed provide energy via $\beta$ oxidation).

FASN has been shown to be one of the downstream effectors of the PTEN/PI3K/AKT pathway in the PC cell line LNCaP (43). Similarly, Migita et al demonstrated that forced overexpression of FASN increased cell proliferation both in vitro and in vivo, dependent on the presence of AR in the PC cells (44). Knock down of FASN in the same cells triggered apoptosis, suggesting that FASN can act as an oncogene in the presence of AR, and that FASN exerts its oncogenic influence by inhibiting apoptosis.

P300 (also known as EP300 or E1a binding protein 300) is an acetlytransferase that acts as a transcription co-activator and has been linked to PC growth. It is known to acetylate histone H3 lysine 27 (H3K27Ac) within the FASN gene promoter region, and studies have demonstrated that it acts to increase FASN expression, driving lipid accumulation and PC cell growth (45). Immumohistochemical (IHC) studies of FASN expression suggest that it is one of the earliest and commonest events in the development of PC $(46,47)$. As the 
disease progresses, FASN levels correlate with Gleason Scores (tumour differentiation) and PSA levels (48).

Upon epithelial to mesenchymal transition (EMT), a process crucial for metastasis, FASN levels appear to rise along with increases in lipid droplet and triacylglycerides (TAG) formation in DU145 PC cells (49). It remains unclear what role FASN plays in EMT or what the TAGs contained inside the lipid droplets are doing, but it is possible that the accumulation of stored TAGs may contribute to EMT through provision of fuel source with the generation of ATP as well as biomass for membrane synthesis (5). Inhibition of FASN has been observed to suppress both proliferation and key EMT phenotypes including cell adhesion, migration and invasion (50). FASN knockdown is observed to reduce the synthesis of phospholipids and triglycerides but not cholesterol (6).

Androgens have been observed to induce FASN expression and subsequent lipid accumulation in vitro in multiple PC cell lines (51). It is probable that this effect is presided over by SREBP and/or PPARG, however other androgen regulated factors may also have a role to play. Androgens may exert their effect on FASN through their ability to increase expression of ubiquitin-specific protease-2a (USP2a), an isopeptidase, which is able to stabilise FASN by deubiquitinating it at a preproteasomal level (52). Thus, androgens can induce FASN expression both through activation of SREBP and PPARG, but also further downstream by stabilisation of the resultant protein, allowing PC cells to achieve even greater levels of FASN expression. Aside from androgens, FASN expression has also been linked hypoxia due through the activation of Akt and SREBP1 in breast cancer, another hormone driven cancer (53). 
The specific oncogenic nature of FASN in PC seems to mark it out as an ideal candidate for drug development (41). Its increased levels and function correlating with the most aggressive forms of the disease give promise that such a treatment would potentially be useful at all stages, from chemoprevention up to even the most severe cases.

\section{Stearoyl-CoA desaturase 1 (SCD1)}

$\operatorname{SCD} 1(\Delta-9$-destaurase) is an endoplasmic reticulum (ER) enzyme that catalyses the rate-limiting step in the formation of mono-unsaturated FAs (MUFAs) from stearoyl-CoA and palmitoyl-CoA (54). These MUFAs (oleate and palmitoleate) are major components of membrane phospholipids and cholesterol esters. SCD1 is a key enzyme in FA metabolism, introducing a double bond at the $\Delta 9$ position in newly synthesised FAs.

Like FASN, SCD1 expression is regulated by SREBP. FASN acts upstream to produce saturated FAs, which SCD1 can then unsaturate. A recent study demonstrated that SCD1 inhibition altered the cellular lipid composition, and importantly impeded cell viability in the absence of exogenous lipids (55). Inhibition also altered cardiolipin composition, leading to the release of cytochrome $\mathrm{C}$ and induction of apoptosis. Silencing of SCD1 expression in a prostate orthograft model using LNCaP cells efficiently blocked tumour growth and significantly increased animal survival (55). This corresponds with previous studies where pharmacological inhibition of SCD1 impaired lipid synthesis by depleting MUFA and slowed PC xenograft growth in nude mice $(56,57)$. 
Despite this it has also been observed that loss of SCD1 function can induce increased ER- and oxidative stress, bought about by accumulation of saturated fatty acids in membrane phospholipids, which induces an unfolded protein response (UPR) (58). Indeed, it has been shown that PC cells have increased levels of membrane lipid saturation which may protect from free radicals and chemotherapeutics (59). Intriguingly, out with its direct role in lipid metabolism, proteolytic cleavage of SCD1 protein generates a small peptide that has been shown to can exert a positive effect on the transcriptional activity of AR $(60)$.

The role of SCD1 in PC therefore seems twofold. Firstly, to function in its capacity as a desaturase to increase the levels of mono-unsaturated lipids in the cancer cell. This can meet the increased need for these lipids in rapidly dividing and growing cells. Secondly, upon proteolytic cleavage of SCD1, a small peptide fragment can enhance AR mediated signalling, thus further promoting PC growth and proliferation. If a therapy can be designed around this peptide it may be represent an opportunity to attenuate the effects of AR on PC.

\section{$\underline{\text { ATP Citrate Lyase (ACLY) and Acetyl-CoA Carboxylase (ACC) }}$}

ACC and ACLY are both up-stream of FASN in the lipid synthesis pathway. ACLY is responsible for the conversion of citrate (derived from the TCA cycle and metabolism of glucose) to acetyl CoA. Linking glucose metabolism to FA synthesis, ACC then takes the acetyl CoA produced by ACLY and converts it to malonyl-CoA, which can then be fed to FASN to generate saturated FA. Knockdown or chemical inhibition of either of these two enzymes has been 
shown to inhibit the growth of a variety of solid tumours, including PC $(6,61$ 64). Both ACC and ACLY expression has been linked to androgens (13). Reduction in ACLY levels by RNAi and the inhibitor SB-204990 has been observed to cause a dramatic reduction in growth of human PC3 orthografts. This is due to their higher rate of glycolysis, and correspondingly high rate of glucose-dependent lipid synthesis, making them sensitive to ACLY inhibition (61).

A recent study has demonstrated that it is possible to target the ACLY-AMPK-AR axes to sensitise CRPC cells to AR antagonism (65). A combined pharmacological approach with an AR antagonist and ACLY inhibition in CRPC cells promotes energetic stress and AMPK activation, resulting in further suppression of AR levels and target gene expression, inhibition of proliferation, and apoptosis.

\section{Gross effects of the adiposity within the tumour microenvironment}

Obesity is a risk factor in many cancers, including PC. Levels in males in developed countries are set to rise to $83 \%$ by 2025 (66). A recent meta-analysis has demonstrated that whilst not significantly correlated with PC incidence (RR, 1.00; 95\% CI, 0.95-1.06), obesity correlates strongly with increased risk of developing aggressive PC (RR, 1.14; 95\% CI, 1.04-1.25) and PC specific mortality (RR, 1.24; 95\% CI, 1.15-2.33) (67).

Knowing that androgens are major drivers of PC, it is surprising that high BMI and visceral/subcutaneous fat content actually inversely correlates with testosterone levels (68). Consequently, in obese men, testosterone (androgen) levels are reduced. Therefore, it is surprising that obesity, as a low testosterone phenotype, correlates with PC growth and development. 
The fat deposit closest to the prostate is the peri-prostatic adipose tissue (PPAT), which is found surrounding the prostate. PPAT volume, measured both on Magnetic Resonance Imaging (MRI) and Ultrasound (US), has been established as a potential biomarker for PC aggressiveness $(69,70)$. Periprostatic fat volume was found to be highest in patients at highest risk of developing Castrate Resistant Prostate Cancer (CRPC). This highlights a potential role of PPAT in predicting the effectiveness of ADT treatment.

It has been observed that PC cells grown in conditioned media (CM) from PPAT have a significant increase in proliferation and motility in vitro $(71,72)$. This effect was specific to PPAT, with factors derived from alternative adipose CM sources showing minimal effect. The specific "adipokines" causing these effects in the PPAT CM has only recently begun to be elucidated. Matrix metalloproteinase (MMP) activity, known to be required for migration and metastasis, has been associated with PPAT (72). PPAT is able to promote tumour growth and migration through increased matrix metalloproteinase activity of MMP2 and MMP9, which are released into the tumour microenvironment (72). Furthermore, the expression level of the adipokine receptor CCR3 was found to increase in tandem with increasing volume of PPAT (69). Similarly, secretion of CCL7 from periprostatic adipocytes was found to promote the migration of CCR3 expressing PC cells in vitro and in vivo (73). In obesity, there is higher secretion of CCL7 by cancer associated adipocytes (CAA), which may mechanistically promote the development of locally advanced disease. The increased migration of PC cells was inhibited with suppression of the CCR3/CCL7 axis. Clinically, increasing expression of CCR3 is associated with 
higher Gleason Sum Score, higher pathological tumour (T) stage, lymph node invasion and an increased risk of biochemical recurrence (73).

A variety of pro-inflammatory cytokines and chemokines are found to increase relative to levels of obesity; one such chemokine IL-6 has been shown to be associated with PC $(74,75)$ with increasing levels correlating with advanced aggressive castrate resistant metastatic disease $(76,77)$. IL-6 is produced by the adipose tissue surrounding the prostate, such as the PPAT, and is involved in regulation of proliferative responses and cell death (78). Following migration of tumour cells along this chemokine (IL-6) gradient and upon contact with the PPAT, it appears that PPAT volume is reduced, which may be due to re-modelling of the PPAT by the invading tumour (73). However, given that tumour cells have been observed to induce lipolysis in neighbouring adipocytes and thus parasitise their lipid stores to fuel tumour growth and proliferation $(79,80)$, it is also possible that this loss of PPAT upon contact with tumour is a result of the tumour utilising the fuel stored there to grow and divide.

Another fat deposit utilised by PC cells is bone marrow adipocytes. Given bone is a site to which PC preferentially metastasises, it raises the question as to whether this is related to the presence of the marrow fat cells. It is similarly hypothesised the reason that PC metastasises at a later stage compared to other cancers is because of the relative abundance of locally accessible fat stores, and only when these are exhausted do the PC cell metastasise to within proximity of local lipid rich marrow fat cells. These PC cells can then induce the marrow fat cells to undergo lipolysis, releasing free FAs and glycerol, the latter of which can 
then feed into the glycolytic pathway of the PC cells (81). Highlighting the impact of tumour micro-environment, bone marrow adipocytes can alter the gene expression profile of PC cells to enhance utilisation of the glycolytic pathway with concurrent increase in lactate production, indicating a shift to a glycolytic metabolic profile, which is consistent with the Warburg Phenotype (81).

\section{$\underline{\text { Fat metabolism targeted treatments for prostate cancer }}$}

With the evidence linking PC to lipid metabolism growing, a number of treatment strategies targeting various stages of the pathway have been investigated.

Silibinin is compound that is isolated from the seeds of the milk thistle plant and is widely consumed for the liver health benefits it offers, including its use as a potential treatment in PC (82). Silibinin activates AMPK, which in turn phosphorylates SREBP preventing SREBP cleavage and its subsequent nuclear translocation and resultant activation of SREBP target genes $(83,84)$. This reduces lipid and cholesterol content in PC cells compared to benign prostate epithelial cells, making it a PC specific treatment option (84). Inactivation of SREBP1 by silibinin causes downstream reduction in expression levels and activities of multiple lipid and cholesterol metabolic genes; among them are FASN, ACYL, ACC, AMACR (an isomerase involved in the $\beta$-oxidation pathway of fatty acids) and HMGCR (an enzyme that is the rate limiting step in the mevalonate pathway that produces cholesterol) (83). Thus, silibinin acts to inhibit both lipid metabolism and cholesterol synthesis through SREBP 
inhibition, halting proliferation and inducing cell cycle arrest, as well as preventing the development of androgen resistance in PC cells (84).

Another molecule, Fatostatin, a synthetic diarylthiazole derivative, is known to block adipogeneis through inhibition of SREBP (85). It has been observed to bind to SCAP, the escort protein of SREBP, blocking the ER-Golgi translocation of SREBP, and thus preventing its activation (85). Whilst this work has not been performed in PC, it represents another potential mechanism for blocking SREBP activation (86).

When considering PPARG we have already mentioned the differing opinions upon its role as an oncogene or a tumour suppressor. The evidence supporting its role as a tumour suppressor advocates the use of PPARG synthetic agonists for treatment of PC. Thiazolidinediones (TZDs) are synthetic PPARG agonists and have been successfully used in the treatment of type II diabetes, for review see (87). The premise behind their use being that upon treatment with TZD's PPARG is activated and in a dose dependant manner relieving the effects of hyperglycaemia. However further research has discovered that the concentrations at which TZD's are being used to treat diabetes is far higher than required for the full activation of PPARG (88). When applied at more physiologic (lower) concentrations for full PPARG activation, TZD was in fact protective against apoptosis, possibly through enhancing the cells' ability to maintain the mitochondrial membrane potential (88). This suggests that treatment with TZD's at high concentrations is not necessarily resulting in specifically PPARG driven effect and indeed the activation of PPARG in this context may be 
counterintuitive. Recent work now appears to suggest that PPARG activation may be tumourigenic in PC $(32,33)$, and compounding this with the fact that those suffering type II diabetes are often overweight/obese, then an activation of PPARG by TZD could accelerate tumourigenesis.

Conflicting evidence surrounds the role of statins in PC, reviewed in (89). Studies of PC cell lines and animal models have shown that statins have antitumourigenic potential, by inhibiting proliferation and growth of PC cells (90, 91). Recent Danish registry based studies also demonstrated a positive role of statins in reducing PC mortality, both pre-and post-diagnosis $(92,93)$. A UK registry based study found that post-diagnosis statin use was associated with reduced PC mortality, particularly among patients who had used it prior to the diagnosis of PC (94). Two meta-analyses failed to find an association between statin use and PC recurrence among patients following radical prostatectomy or radiotherapy $(95,96)$. In contrast, a more recent meta-analysis demonstrated up to $25 \%$ risk reductions for PSA recurrence, and both PC-specific and overall survival (97). The recent Finnish Randomised Study for PC screening showed no reduction in PC mortality with pre-diagnosis statin use, whereas post-diagnosis use was associated with reduced mortality, especially in patients on Androgen Deprivation Treatment (ADT) (98). Another recent study examining selection bias found that once this was accounted for, statin use within 6 months of cancer diagnosis did notappear to improve 3-year cancer specific survival or overall survival (99). 
FASN is now accepted as a bona fide oncogene. Inhibition of FASN has been found to cause selective apoptosis of cancer cell in multiple cancer types (100), however the mechanism behind this remains unclear. It is possible that loss of FASN affects membrane function, DNA replication or inhibition of anti-apoptotic proteins and/or the accumulation of Malonyl-CoA (101). The selective apoptotic effects caused by loss of FASN activity on cancer cells make it an attractive target for therapy. Cerulenin, a naturally derived inhibitor of FASN, is produced by a fungus Cephalosporum caerulens. Cerulenin binds the B-ketoacyl synthase domain of FASN to suppress its function. It is highly potent but is also unstable with toxic side effects. The synthetic analogue C75 of cerulenin was developed with a better side effect profile and greater stability (102). However, the major side effect of both $\mathrm{C75}$ (and cerlenin) is dramatic and rapid weight loss seemingly resulting from stimulation of carnitine palmitoyltransferase-1 (CPT1), which activates mitochondrial fatty acid oxidation, is the limiting factor in developing these agents as cancer therapies $(102,103)$.

Novel combination strategies with co-inhibition of FASN and AMPK have also been explored in pre-clinical models, with the use of AMPK inhibitor compound C (cC) and C75. Blocking lipid synthesis with concurrent AMPK inhibition, results in accumulation of toxic metabolites such as malonyl-CoA and NADPH as well as generating of toxic reactive oxygen species (ROS) inducing apoptosis and arrest of tumour cell proliferation (104).

Another naturally occurring FASN inhibitor exists in the form of various plant flavonoids, one of which is found in green tea, namely Epigallocatechin-3-gallate (EGCG). EGCG has been shown to block the formation of tumours in a range of 
animal models (105). Similar to treatments with C75 and cerlenin, EGCG treatment also resulted excessive and speedy weight loss, possibly through activation of CPT1 (103). The use of CPT1 inhibitors such as etomoxir result in reduced PC growth in vitro and in vivo, so combination therapy with FASN inhibitors may allow inhibition of tumour growth whilst mitigating the unwanted side effects of weight loss. (106).

Orlistat, an anti-obesity drug, has also been found to inhibit the thioesterase domain of FASN; thus halting PC cell proliferation, inducing apoptosis and reducing tumour cell growth in nude mice (107). In its current formulation, Orlistat is limited as an anti-cancer therapy. It has a poor solubility and bioavailability, and when given orally is only functional in the areas it directly comes into contact with, inhibiting pancreatic lipases in the gut (107) .

TVB-2640 is the first-in-class, small molecule reversible inhibitor of FASN that demonstrates Phase I clinical efficacy in KRAS mutant NSCLC, ovarian and breast cancer $(108,109)$. In this trial, prolonged stable disease was seen with monotherapy. In addition, when given in combination with paclitaxel, there is evidence of prolonged stable disease in both NSCLC and breast cancer patients, with a confirmed partial response in an patient with peritoneal serous carcinoma (108).

\section{$\underline{\text { Conclusions }}$}

The link between PC and fat metabolism is well established, with AR intimately involved as up- and down-stream factors (mediators) for a number of metabolic 
enzymes. Furthermore, the evidence surrounding the risk of developing more advanced and aggressive PC with increased obesity and gross fat volume surrounding the prostate suggests the importance of lipid pathways not only on primary tumour growth but also on the development of advanced and metastatic disease.

Despite this, there is a paucity of agents in clinical trials for PC. It is likely that these agents will form part of combination drug strategies, with targeting of multiple metabolic pathways (e.g. FASN and CPT1), or in combination with AR pathway inhibitors (SCD1 and AR). Pre-clinical studies suggest this may improve "cancer kill" whilst reducing the toxic side effect profile. 
1. Siegel RL, Miller KD, Jemal A. Cancer statistics, 2015. CA Cancer J Clin. 2015;65(1):5-29.

2. Huggins $\mathrm{CaH}, \mathrm{C} . \mathrm{V}$. Studies on Prostatic Cancer: I. The effect of castration, of estrogen, and of androgen injection on serum phosphatases in metastatic carcinoma of the prostate. Cancer Res. 1941;1(4):293 -297.

3. Feldman BJ, Feldman D. The development of androgen-independent prostate cancer. Nat Rev Cancer. 2001;1(1):34-45.

4. Medes G, Thomas A, Weinhouse S. Metabolism of neoplastic tissue. IV. A study of lipid synthesis in neoplastic tissue slices in vitro. Cancer Res. 1953;13(1):27-29.

5. Jackowski S. Coordination of membrane phospholipid synthesis with the cell cycle. J Biol Chem. 1994;269(5):3858-3867.

6. Brusselmans K, De Schrijver E, Verhoeven G, Swinnen JV. RNA interference-mediated silencing of the acetyl-CoA-carboxylase-alpha gene induces growth inhibition and apoptosis of prostate cancer cells. Cancer Res. 2005;65(15):6719-6725.

7. Swinnen JV, Vanderhoydonc F, Elgamal AA, Eelen M, Vercaeren I, Joniau S, Van Poppel H, Baert L, Goossens K, Heyns W, Verhoeven G. Selective activation of the fatty acid synthesis pathway in human prostate cancer. Int J Cancer. 2000;88(2):176-179.

8. Simons K, Toomre D. Lipid rafts and signal transduction. Nat Rev Mol Cell Biol. 2000;1(1):31-39.

9. Manes S, Mira E, Gomez-Mouton C, Lacalle RA, Keller P, Labrador JP, Martinez AC. Membrane raft microdomains mediate front-rear polarity in migrating cells. EMBO J. 1999;18(22):6211-6220.

10. Ikonen E, Simons K. Protein and lipid sorting from the trans-Golgi network to the plasma membrane in polarized cells. Semin Cell Dev Biol. 1998;9(5):503-509.

11. Yue S, Li J, Lee SY, Lee HJ, Shao T, Song B, Cheng L, Masterson TA, Liu X, Ratliff TL, Cheng JX. Cholesteryl ester accumulation induced by PTEN loss and PI3K/AKT activation underlies human prostate cancer aggressiveness. Cell Metab. 2014;19(3):393-406.

12. Swinnen JV, Van Veldhoven PP, Esquenet M, Heyns W, Verhoeven G. Androgens markedly stimulate the accumulation of neutral lipids in the human prostatic adenocarcinoma cell line LNCaP. Endocrinology. 1996;137(10):44684474 . 
13. Swinnen JV, Ulrix W, Heyns W, Verhoeven G. Coordinate regulation of lipogenic gene expression by androgens: evidence for a cascade mechanism involving sterol regulatory element binding proteins. Proc Natl Acad Sci U S A. 1997;94(24):12975-12980.

14. Liu Y, Zuckier LS, Ghesani NV. Dominant uptake of fatty acid over glucose by prostate cells: a potential new diagnostic and therapeutic approach. Anticancer Res. 2010;30(2):369-374.

15. Shao W, Espenshade PJ. Expanding roles for SREBP in metabolism. Cell Metab. 2012;16(4):414-419.

16. Heemers H, Verrijdt G, Organe S, Claessens F, Heyns W, Verhoeven G, Swinnen JV. Identification of an androgen response element in intron 8 of the sterol regulatory element-binding protein cleavage-activating protein gene allowing direct regulation by the androgen receptor. J Biol Chem. 2004;279(29):30880-30887.

17. Nohturfft A, Zhang SC. Coordination of lipid metabolism in membrane biogenesis. Annu Rev Cell Dev Biol. 2009;25:539-566.

18. Huang WC, Zhau HE, Chung LW. Androgen receptor survival signaling is blocked by anti-beta2-microglobulin monoclonal antibody via a MAPK/lipogenic pathway in human prostate cancer cells. J Biol Chem. 2010;285(11):7947-7956.

19. Hughes AL, Todd BL, Espenshade PJ. SREBP pathway responds to sterols and functions as an oxygen sensor in fission yeast. Cell. 2005;120(6):831-842.

20. Porstmann T, Griffiths B, Chung YL, Delpuech O, Griffiths JR, Downward J, Schulze A. PKB/Akt induces transcription of enzymes involved in cholesterol and fatty acid biosynthesis via activation of SREBP. Oncogene. 2005;24(43):64656481.

21. Duvel K, Yecies JL, Menon S, Raman P, Lipovsky AI, Souza AL, Triantafellow E, Ma Q, Gorski R, Cleaver S, Vander Heiden MG, MacKeigan JP, Finan PM, Clish CB, Murphy LO, Manning BD. Activation of a metabolic gene regulatory network downstream of mTOR complex 1. Mol Cell. 2010;39(2):171183.

22. Li Y, Xu S, Mihaylova MM, Zheng B, Hou X, Jiang B, Park O, Luo Z, Lefai E, Shyy JY, Gao B, Wierzbicki M, Verbeuren TJ, Shaw RJ, Cohen RA, Zang M. AMPK phosphorylates and inhibits SREBP activity to attenuate hepatic steatosis and atherosclerosis in diet-induced insulin-resistant mice. Cell Metab. 2011;13(4):376-388.

23. Liu N, Zhao J, Wang J, Teng H, Fu Y, Yuan H. Farnesoid X receptor ligand CDCA suppresses human prostate cancer cells growth by inhibiting lipid metabolism via targeting sterol response element binding protein 1 . Am J Transl Res. 2016;8(11):5118-5124. 
24. Watanabe M, Houten SM, Wang L, Moschetta A, Mangelsdorf DJ, Heyman RA, Moore DD, Auwerx J. Bile acids lower triglyceride levels via a pathway involving FXR, SHP, and SREBP-1c. J Clin Invest. 2004;113(10):1408-1418.

25. Liu J, Tong SJ, Wang X, Qu LX. Farnesoid X receptor inhibits LNcaP cell proliferation via the upregulation of PTEN. Exp Ther Med. 2014;8(4):1209-1212.

26. Sarraf P, Mueller E, Smith WM, Wright HM, Kum JB, Aaltonen LA, de la Chapelle A, Spiegelman BM, Eng C. Loss-of-function mutations in PPAR gamma associated with human colon cancer. Mol Cell. 1999;3(6):799-804.

27. Sarraf P, Mueller E, Jones D, King FJ, DeAngelo DJ, Partridge JB, Holden SA, Chen LB, Singer S, Fletcher C, Spiegelman BM. Differentiation and reversal of malignant changes in colon cancer through PPARgamma. Nat Med. 1998;4(9):1046-1052.

28. Tsubouchi Y, Sano H, Kawahito Y, Mukai S, Yamada R, Kohno M, Inoue K, Hla T, Kondo M. Inhibition of human lung cancer cell growth by the peroxisome proliferator-activated receptor-gamma agonists through induction of apoptosis. Biochem Biophys Res Commun. 2000;270(2):400-405.

29. Kulke MH, Demetri GD, Sharpless NE, Ryan DP, Shivdasani R, Clark JS, Spiegelman BM, Kim H, Mayer RJ, Fuchs CS. A phase II study of troglitazone, an activator of the PPARgamma receptor, in patients with chemotherapy-resistant metastatic colorectal cancer. Cancer J. 2002;8(5):395-399.

30. Wang G, Cao R, Wang Y, Qian G, Dan HC, Jiang W, Ju L, Wu M, Xiao Y, Wang $\mathrm{X}$. Simvastatin induces cell cycle arrest and inhibits proliferation of bladder cancer cells via PPARgamma signalling pathway. Sci Rep. 2016;6:35783.

31. Mueller E, Smith M, Sarraf P, Kroll T, Aiyer A, Kaufman DS, Oh W, Demetri G, Figg WD, Zhou XP, Eng C, Spiegelman BM, Kantoff PW. Effects of ligand activation of peroxisome proliferator-activated receptor gamma in human prostate cancer. Proc Natl Acad Sci U S A. 2000;97(20):10990-10995.

32. Ahmad I, Mui E, Galbraith L, Patel R, Tan EH, Salji M, Rust AG, Repiscak P, Hedley A, Markert E, Loveridge C, van der Weyden L, Edwards J, Sansom OJ, Adams DJ, Leung HY. Sleeping Beauty screen reveals Pparg activation in metastatic prostate cancer. Proc Natl Acad Sci U S A. 2016;113(29):8290-8295.

33. Tew BY, Hong TB, Otto-Duessel M, Elix C, Castro E, He M, Wu X, Pal SK, Kalkum M, Jones JO. Vitamin K epoxide reductase regulation of androgen receptor activity. Oncotarget. 2017;8(8):13818-13831.

34. Saez E, Olson P, Evans RM. Genetic deficiency in Pparg does not alter development of experimental prostate cancer. Nat Med. 2003;9(10):1265-1266.

35. Forootan FS, Forootan SS, Malki MI, Chen D, Li G, Lin K, Rudland PS, Foster CS, Ke Y. The expression of C-FABP and PPARgamma and their prognostic significance in prostate cancer. Int J Oncol. 2014;44(1):265-275. 
36. Bao Z, Malki MI, Forootan SS, Adamson J, Forootan FS, Chen D, Foster CS, Rudland PS, Ke Y. A novel cutaneous Fatty Acid-binding protein-related signaling pathway leading to malignant progression in prostate cancer cells. Genes Cancer. 2013;4(7-8):297-314.

37. Olokpa E, Bolden A, Stewart LV. The Androgen Receptor Regulates PPARgamma Expression and Activity in Human Prostate Cancer Cells. J Cell Physiol. 2016;231(12):2664-2672.

38. Hauner H. The mode of action of thiazolidinediones. Diabetes Metab Res Rev. 2002;18 Suppl 2:S10-15.

39. Akinyeke TO, Stewart LV. Troglitazone suppresses c-Myc levels in human prostate cancer cells via a PPARgamma-independent mechanism. Cancer Biol Ther. 2011;11(12):1046-1058.

40. Bolden A, Bernard L, Jones D, Akinyeke T, Stewart LV. The PPAR Gamma Agonist Troglitazone Regulates Erk 1/2 Phosphorylation via a PPARgammaIndependent, MEK-Dependent Pathway in Human Prostate Cancer Cells. PPAR research. 2012;2012:929052.

41. Flavin R, Peluso S, Nguyen PL, Loda M. Fatty acid synthase as a potential therapeutic target in cancer. Future Oncol. 2010;6(4):551-562.

42. Menendez JA, Lupu R. Fatty acid synthase and the lipogenic phenotype in cancer pathogenesis. Nat Rev Cancer. 2007;7(10):763-777.

43. Van de Sande T, De Schrijver E, Heyns W, Verhoeven G, Swinnen JV. Role of the phosphatidylinositol 3'-kinase/PTEN/Akt kinase pathway in the overexpression of fatty acid synthase in LNCaP prostate cancer cells. Cancer Res. 2002;62(3):642-646.

44. Migita T, Ruiz S, Fornari A, Fiorentino M, Priolo C, Zadra G, Inazuka F, Grisanzio C, Palescandolo E, Shin E, Fiore C, Xie W, Kung AL, Febbo PG, Subramanian A, Mucci L, Ma J, Signoretti S, Stampfer M, Hahn WC, Finn S, Loda M. Fatty acid synthase: a metabolic enzyme and candidate oncogene in prostate cancer. J Natl Cancer Inst. 2009;101(7):519-532.

45. Gang X, Yang Y, Zhong J, Jiang K, Pan Y, Karnes RJ, Zhang J, Xu W, Wang G, Huang H. P300 acetyltransferase regulates fatty acid synthase expression, lipid metabolism and prostate cancer growth. Oncotarget. 2016;7(12):15135-15149.

46. Swinnen JV, Roskams T, Joniau S, Van Poppel H, Oyen R, Baert L, Heyns W, Verhoeven G. Overexpression of fatty acid synthase is an early and common event in the development of prostate cancer. Int J Cancer. 2002;98(1):19-22.

47. Van de Sande T, Roskams T, Lerut E, Joniau S, Van Poppel H, Verhoeven G, Swinnen JV. High-level expression of fatty acid synthase in human prostate cancer tissues is linked to activation and nuclear localization of Akt/PKB. J Pathol. 2005;206(2):214-219. 
48. Hamada S, Horiguchi A, Kuroda K, Ito K, Asano T, Miyai K, Iwaya K. Increased fatty acid synthase expression in prostate biopsy cores predicts higher Gleason score in radical prostatectomy specimen. BMC Clin Pathol. 2014;14(1):3.

49. Dalmau N, Jaumot J, Tauler R, Bedia C. Epithelial-to-mesenchymal transition involves triacylglycerol accumulation in DU145 prostate cancer cells. Mol Biosyst. 2015;11(12):3397-3406.

50. Yoshii Y, Furukawa T, Oyama N, Hasegawa Y, Kiyono Y, Nishii R, Waki A, Tsuji AB, Sogawa C, Wakizaka H, Fukumura T, Yoshii H, Fujibayashi Y, Lewis JS, Saga T. Fatty acid synthase is a key target in multiple essential tumor functions of prostate cancer: uptake of radiolabeled acetate as a predictor of the targeted therapy outcome. PLoS One. 2013;8(5):e64570.

51. Swinnen JV, Esquenet M, Goossens K, Heyns W, Verhoeven G. Androgens stimulate fatty acid synthase in the human prostate cancer cell line LNCaP. Cancer Res. 1997;57(6):1086-1090.

52. Graner E, Tang D, Rossi S, Baron A, Migita T, Weinstein LJ, Lechpammer M, Huesken D, Zimmermann J, Signoretti S, Loda M. The isopeptidase USP2a regulates the stability of fatty acid synthase in prostate cancer. Cancer Cell. 2004;5(3):253-261.

53. Furuta E, Pai SK, Zhan R, Bandyopadhyay S, Watabe M, Mo YY, Hirota S, Hosobe S, Tsukada T, Miura K, Kamada S, Saito K, Iiizumi M, Liu W, Ericsson J, Watabe K. Fatty acid synthase gene is up-regulated by hypoxia via activation of Akt and sterol regulatory element binding protein-1. Cancer Res. 2008;68(4):1003-1011.

54. Paton CM, Ntambi JM. Biochemical and physiological function of stearoylCoA desaturase. Am J Physiol Endocrinol Metab. 2009;297(1):E28-37.

55. Peck B, Schug ZT, Zhang Q, Dankworth B, Jones DT, Smethurst E, Patel R, Mason S, Jiang M, Saunders R, Howell M, Mitter R, Spencer-Dene B, Stamp G, McGarry L, James D, Shanks E, Aboagye EO, Critchlow SE, Leung HY, Harris AL, Wakelam MJ, Gottlieb E, Schulze A. Inhibition of fatty acid desaturation is detrimental to cancer cell survival in metabolically compromised environments. Cancer Metab. 2016;4:6.

56. Fritz V, Benfodda Z, Rodier G, Henriquet C, Iborra F, Avances C, Allory Y, de la Taille A, Culine S, Blancou H, Cristol JP, Michel F, Sardet C, Fajas L. Abrogation of de novo lipogenesis by stearoyl-CoA desaturase 1 inhibition interferes with oncogenic signaling and blocks prostate cancer progression in mice. Mol Cancer Ther. 2010;9(6):1740-1754.

57. Mason P, Liang B, Li L, Fremgen T, Murphy E, Quinn A, Madden SL, Biemann HP, Wang B, Cohen A, Komarnitsky S, Jancsics K, Hirth B, Cooper CG, Lee E, Wilson S, Krumbholz R, Schmid S, Xiang Y, Booker M, Lillie J, Carter K. SCD1 inhibition causes cancer cell death by depleting mono-unsaturated fatty acids. PLoS One. 2012;7(3):e33823. 
58. Ariyama H, Kono N, Matsuda S, Inoue T, Arai H. Decrease in membrane phospholipid unsaturation induces unfolded protein response. J Biol Chem. 2010;285(29):22027-22035.

59. Rysman E, Brusselmans K, Scheys K, Timmermans L, Derua R, Munck S, Van Veldhoven PP, Waltregny D, Daniels VW, Machiels J, Vanderhoydonc F, Smans K, Waelkens E, Verhoeven G, Swinnen JV. De novo lipogenesis protects cancer cells from free radicals and chemotherapeutics by promoting membrane lipid saturation. Cancer Res. 2010;70(20):8117-8126.

60. Kim SJ, Choi H, Park SS, Chang C, Kim E. Stearoyl CoA desaturase (SCD) facilitates proliferation of prostate cancer cells through enhancement of androgen receptor transactivation. Mol Cells. 2011;31(4):371-377.

61. Hatzivassiliou G, Zhao F, Bauer DE, Andreadis C, Shaw AN, Dhanak D, Hingorani SR, Tuveson DA, Thompson CB. ATP citrate lyase inhibition can suppress tumor cell growth. Cancer Cell. 2005;8(4):311-321.

62. Bauer DE, Hatzivassiliou G, Zhao F, Andreadis C, Thompson CB. ATP citrate lyase is an important component of cell growth and transformation. Oncogene. 2005;24(41):6314-6322.

63. Pearce NJ, Yates JW, Berkhout TA, Jackson B, Tew D, Boyd H, Camilleri P, Sweeney P, Gribble AD, Shaw A, Groot PH. The role of ATP citrate-lyase in the metabolic regulation of plasma lipids. Hypolipidaemic effects of SB-204990, a lactone prodrug of the potent ATP citrate-lyase inhibitor SB-201076. Biochem J. 1998;334 ( Pt 1):113-119.

64. Migita T, Narita T, Nomura K, Miyagi E, Inazuka F, Matsuura M, Ushijima M, Mashima T, Seimiya H, Satoh Y, Okumura S, Nakagawa K, Ishikawa Y. ATP citrate lyase: activation and therapeutic implications in non-small cell lung cancer. Cancer Res. 2008;68(20):8547-8554.

65. Shah S, Carriveau WJ, Li J, Campbell SL, Kopinski PK, Lim HW, Daurio N, Trefely S, Won KJ, Wallace DC, Koumenis C, Mancuso A, Wellen KE. Targeting ACLY sensitizes castration-resistant prostate cancer cells to AR antagonism by impinging on an ACLY-AMPK-AR feedback mechanism. Oncotarget. 2016;7(28):43713-43730.

66. Wilson KM, Giovannucci EL, Mucci LA. Lifestyle and dietary factors in the prevention of lethal prostate cancer. Asian J Androl. 2012;14(3):365-374.

67. Zhang X, Zhou G, Sun B, Zhao G, Liu D, Sun J, Liu C, Guo H. Impact of obesity upon prostate cancer-associated mortality: A meta-analysis of 17 cohort studies. Oncol Lett. 2015;9(3):1307-1312.

68. Chavarro JE, Toth TL, Wright DL, Meeker JD, Hauser R. Body mass index in relation to semen quality, sperm DNA integrity, and serum reproductive hormone levels among men attending an infertility clinic. Fertil Steril. 2010;93(7):2222-2231. 

Volume Measurement as a Predictive Tool for Castration Resistance in Advanced Prostate Cancer. Eur Urol Focus. 2017.

70. Bhindi B, Trottier G, Elharram M, Fernandes KA, Lockwood G, Toi A, Hersey KM, Finelli A, Evans A, van der Kwast TH, Fleshner NE. Measurement of peri-prostatic fat thickness using transrectal ultrasonography (TRUS): a new risk factor for prostate cancer. BJU Int. 2012;110(7):980-986.

71. Venkatasubramanian PN, Brendler CB, Plunkett BA, Crawford SE, Fitchev PS, Morgan G, Cornwell ML, McGuire MS, Wyrwicz AM, Doll JA. Periprostatic adipose tissue from obese prostate cancer patients promotes tumor and endothelial cell proliferation: a functional and MR imaging pilot study. Prostate. 2014;74(3):326-335.

72. Ribeiro R, Monteiro C, Cunha V, Oliveira MJ, Freitas M, Fraga A, Principe P, Lobato C, Lobo F, Morais A, Silva V, Sanches-Magalhaes J, Oliveira J, Pina F, MotaPinto A, Lopes C, Medeiros R. Human periprostatic adipose tissue promotes prostate cancer aggressiveness in vitro. J Exp Clin Cancer Res. 2012;31:32.

73. Laurent V, Guerard A, Mazerolles C, Le Gonidec S, Toulet A, Nieto L, Zaidi F, Majed B, Garandeau D, Socrier Y, Golzio M, Cadoudal T, Chaoui K, Dray C, Monsarrat B, Schiltz O, Wang YY, Couderc B, Valet P, Malavaud B, Muller C. Periprostatic adipocytes act as a driving force for prostate cancer progression in obesity. Nat Commun. 2016;7:10230.

74. Weisberg SP, McCann D, Desai M, Rosenbaum M, Leibel RL, Ferrante AW, Jr. Obesity is associated with macrophage accumulation in adipose tissue. J Clin Invest. 2003;112(12):1796-1808.

75. Culig Z. Proinflammatory cytokine interleukin-6 in prostate carcinogenesis. Am J Clin Exp Urol. 2014;2(3):231-238.

76. Adler HL, McCurdy MA, Kattan MW, Timme TL, Scardino PT, Thompson TC. Elevated levels of circulating interleukin- 6 and transforming growth factorbeta1 in patients with metastatic prostatic carcinoma. J Urol. 1999;161(1):182187.

77. Wise GJ, Marella VK, Talluri G, Shirazian D. Cytokine variations in patients with hormone treated prostate cancer. J Urol. 2000;164(3 Pt 1):722-725.

78. Yu SH, Zheng Q, Esopi D, Macgregor-Das A, Luo J, Antonarakis ES, Drake CG, Vessella R, Morrissey C, De Marzo AM, Sfanos KS. A Paracrine Role for IL6 in Prostate Cancer Patients: Lack of Production by Primary or Metastatic Tumor Cells. Cancer Immunol Res. 2015;3(10):1175-1184.

79. Duncan RE, Ahmadian M, Jaworski K, Sarkadi-Nagy E, Sul HS. Regulation of lipolysis in adipocytes. Annu Rev Nutr. 2007;27:79-101.

80. Nieman KM, Kenny HA, Penicka CV, Ladanyi A, Buell-Gutbrod R, Zillhardt MR, Romero IL, Carey MS, Mills GB, Hotamisligil GS, Yamada SD, Peter ME, Gwin 
K, Lengyel E. Adipocytes promote ovarian cancer metastasis and provide energy for rapid tumor growth. Nat Med. 2011;17(11):1498-1503.

81. Diedrich JD, Rajagurubandara E, Herroon MK, Mahapatra G, Huttemann M, Podgorski I. Bone marrow adipocytes promote the Warburg phenotype in metastatic prostate tumors via HIF-1alpha activation. Oncotarget.

2016;7(40):64854-64877.

82. Deep G, Agarwal R. Targeting tumor microenvironment with silibinin: promise and potential for a translational cancer chemopreventive strategy. Curr Cancer Drug Targets. 2013;13(5):486-499.

83. Nambiar DK, Rajamani P, Singh RP. Silibinin attenuates ionizing radiationinduced pro-angiogenic response and EMT in prostate cancer cells. Biochem Biophys Res Commun. 2015;456(1):262-268.

84. Nambiar DK, Deep G, Singh RP, Agarwal C, Agarwal R. Silibinin inhibits aberrant lipid metabolism, proliferation and emergence of androgenindependence in prostate cancer cells via primarily targeting the sterol response element binding protein 1. Oncotarget. 2014;5(20):10017-10033.

85. Kamisuki S, Mao Q, Abu-Elheiga L, Gu Z, Kugimiya A, Kwon Y, Shinohara T, Kawazoe Y, Sato S, Asakura K, Choo HY, Sakai J, Wakil SJ, Uesugi M. A small molecule that blocks fat synthesis by inhibiting the activation of SREBP. Chem Biol. 2009;16(8):882-892.

86. Siqingaowa, Sekar S, Gopalakrishnan V, Taghibiglou C. Sterol regulatory element-binding protein 1 inhibitors decrease pancreatic cancer cell viability and proliferation. Biochem Biophys Res Commun. 2017;488(1):136-140.

87. Olefsky JM. Treatment of insulin resistance with peroxisome proliferatoractivated receptor gamma agonists. J Clin Invest. 2000;106(4):467-472.

88. Wang YL, Frauwirth KA, Rangwala SM, Lazar MA, Thompson CB. Thiazolidinedione activation of peroxisome proliferator-activated receptor gamma can enhance mitochondrial potential and promote cell survival. J Biol Chem. 2002;277(35):31781-31788.

89. Alfaqih MA, Allott EH, Hamilton RJ, Freeman MR, Freedland SJ. The current evidence on statin use and prostate cancer prevention: are we there yet? Nature reviews Urology. 2017;14(2):107-119.

90. Murtola TJ, Pennanen P, Syvala H, Blauer M, Ylikomi T, Tammela TL. Effects of simvastatin, acetylsalicylic acid, and rosiglitazone on proliferation of normal and cancerous prostate epithelial cells at therapeutic concentrations. Prostate. 2009;69(9):1017-1023.

91. Hoque A, Chen $\mathrm{H}, \mathrm{Xu}$ XC. Statin induces apoptosis and cell growth arrest in prostate cancer cells. Cancer Epidemiol Biomarkers Prev. 2008;17(1):88-94. 
92. Nielsen SF, Nordestgaard BG, Bojesen SE. Statin use and reduced cancerrelated mortality. N Engl J Med. 2012;367(19):1792-1802.

93. Larsen SB, Dehlendorff C, Skriver C, Dalton SO, Jespersen CG, Borre M, Brasso K, Norgaard M, Johansen C, Sorensen HT, Hallas J, Friis S. Postdiagnosis Statin Use and Mortality in Danish Patients With Prostate Cancer. J Clin Oncol. 2017:JC02016718981.

94. Yu O, Eberg M, Benayoun S, Aprikian A, Batist G, Suissa S, Azoulay L. Use of statins and the risk of death in patients with prostate cancer. J Clin Oncol. 2014;32(1):5-11.

95. Scosyrev E, Tobis S, Donsky H, Wu G, Joseph J, Rashid H, Messing E. Statin use and the risk of biochemical recurrence of prostate cancer after definitive local therapy: a meta-analysis of eight cohort studies. BJU Int. 2013;111(3 Pt B):E71-77.

96. Park HS, Schoenfeld JD, Mailhot RB, Shive M, Hartman RI, Ogembo R, Mucci LA. Statins and prostate cancer recurrence following radical prostatectomy or radiotherapy: a systematic review and meta-analysis. Ann Oncol. 2013;24(6):1427-1434.

97. Raval AD, Thakker D, Negi H, Vyas A, Salkini MW. Association between statins and clinical outcomes among men with prostate cancer: a systematic review and meta-analysis. Prostate Cancer Prostatic Dis. 2016;19(2):222.

98. Murtola TJ, Peltomaa AI, Talala K, Maattanen L, Taari K, Tammela TLJ, Auvinen A. Statin Use and Prostate Cancer Survival in the Finnish Randomized Study of Screening for Prostate Cancer. Eur Urol Focus. 2016.

99. Emilsson L, Garcia-Albeniz X, Logan RW, Caniglia EC, Kalager M, Hernan MA. Examining Bias in Studies of Statin Treatment and Survival in Patients With Cancer. JAMA Oncol. 2017.

100. Kuhajda FP. Fatty acid synthase and cancer: new application of an old pathway. Cancer Res. 2006;66(12):5977-5980.

101. Pizer ES, Thupari J, Han WF, Pinn ML, Chrest FJ, Frehywot GL, Townsend CA, Kuhajda FP. Malonyl-coenzyme-A is a potential mediator of cytotoxicity induced by fatty-acid synthase inhibition in human breast cancer cells and xenografts. Cancer Res. 2000;60(2):213-218.

102. Kuhajda FP, Pizer ES, Li JN, Mani NS, Frehywot GL, Townsend CA. Synthesis and antitumor activity of an inhibitor of fatty acid synthase. Proc Natl Acad Sci U S A. 2000;97(7):3450-3454.

103. Nicot C, Napal L, Relat J, Gonzalez S, Llebaria A, Woldegiorgis G, Marrero PF, Haro D. C75 activates malonyl-CoA sensitive and insensitive components of the CPT system. Biochem Biophys Res Commun. 2004;325(3):660-664. 
104. Fritz V, Benfodda Z, Henriquet C, Hure S, Cristol JP, Michel F, Carbonneau MA, Casas F, Fajas L. Metabolic intervention on lipid synthesis converging pathways abrogates prostate cancer growth. Oncogene. 2013;32(42):5101-5110.

105. Yang CS, Wang X, Lu G, Picinich SC. Cancer prevention by tea: animal studies, molecular mechanisms and human relevance. Nat Rev Cancer. 2009;9(6):429-439.

106. Schlaepfer IR, Rider L, Rodrigues LU, Gijon MA, Pac CT, Romero L, Cimic A, Sirintrapun SJ, Glode LM, Eckel RH, Cramer SD. Lipid catabolism via CPT1 as a therapeutic target for prostate cancer. Mol Cancer Ther. 2014;13(10):23612371.

107. Kridel SJ, Axelrod F, Rozenkrantz N, Smith JW. Orlistat is a novel inhibitor of fatty acid synthase with antitumor activity. Cancer Res. 2004;64(6):20702075.

108. Dean EJ, Falchook GS, Patel MR, Brenner AJ, Infante JR, Arkenau HT, Borazanci EH, Lopez JS, Pant S, Schmid P, Frankel AE, Jones SF, McCulloch W, Kemble G, O'Farrell M, H. B. Preliminary activity in the first in human study of the first-in-class fatty acid synthase (FASN) inhibitor, TVB-2640. J Clin Oncol. 2016;34(Supplement):2512.

109. O'Farrell M, Heuer T, Grimmer K, Crowley R, Waszczuk J, Fridlib M, Ventura R, Rubio C, Lai J, Buckley D, McCulloch W, Kemble G. Abstract LB-214: FASN inhibitor TVB-2640 shows pharmacodynamic effect and evidence of clinical activity in KRAS-mutant NSCLC patients in a phase I study. Cancer Res. 2016;76(14 Supplement). 
Figure 1: Interaction of lipid pathways in prostate cancer

Some key regulatory proteins PPARG, SREBP and SCAP (red ellipses) govern fatty acid metabolism, the activity of these three is observed to fall under the overall control of Androgens and Androgen Receptor activation (blue ellipse, solid black arrows). Downstream of this hub of control (solid black arrows) are the effector of lipid synthesis, ACC, ACLY, FASN and SCD1 (red ellipses with dashed black arrows showing progression through the pathway), up-regulation of these effectors is also implicated in Prostate Cancer (PC) progression. Several therapeutic agents, Warfarin, Fatostatin, Orlistat (green rectangles red lines) are known to block key processes in lipid metabolism and have a negative effect on PC progression. In addition to those proteins resident within the prostate tumour cells themselves, within the microenvironment including nearby periprostatic fat, there are various other factors (yellow ellipses) that promote prostate cancer growth and progression. Matrix metallo-proteases, MMP2 and MMP9 promote metastasis whilst CCL7 and CCR3 have been linked to generation of an adipokine gradient giving directionality to tumour cell migration. 
Table 1: Key lipid regulating genes

\begin{tabular}{|c|l|}
\hline Gene & \multicolumn{1}{|c|}{ Function } \\
\hline SREBP1 & $\begin{array}{l}\text { Transcription factor, binding sterol regulatory element- } \\
1 \text { (SRE1) sites. Activity is governed by AR. It governs } \\
\text { lipid homeostasis and metabolism as well as sterol } \\
\text { biosynthesis. }\end{array}$ \\
\hline PPARG & $\begin{array}{l}\text { Transcription factor of the nuclear hormone receptor } \\
\text { family, binding PPAR response elements (PPRE). It } \\
\text { governs the activity of genes involved in lipid } \\
\text { metabolism and adipocyte differentiation. }\end{array}$ \\
\hline FASN & $\begin{array}{l}\text { Enzyme responsible for the generation of long chain } \\
\text { saturated fatty acids from acetyl-CoA and malonyl-CoA. }\end{array}$ \\
\hline SCD1 & $\begin{array}{l}\text { Enzyme downstream of FASN responsible for the rate } \\
\text { limiting step of converting of saturated fatty acids to } \\
\text { unsaturated fatty acids, by insertion of a double bond at } \\
\text { the } \Delta 9 \text { position. }\end{array}$ \\
\hline ACLY & $\begin{array}{l}\text { Enzyme upstream of FASN responsible for the } \\
\text { conversion of citrate to acetyl-CoA. }\end{array}$ \\
\hline ACC & $\begin{array}{l}\text { Enzyme that bridges the gap between ACLY and FASN, } \\
\text { responsible for conversion of acetyl Co-A to malonyl- } \\
\text { CoA. }\end{array}$ \\
\hline
\end{tabular}




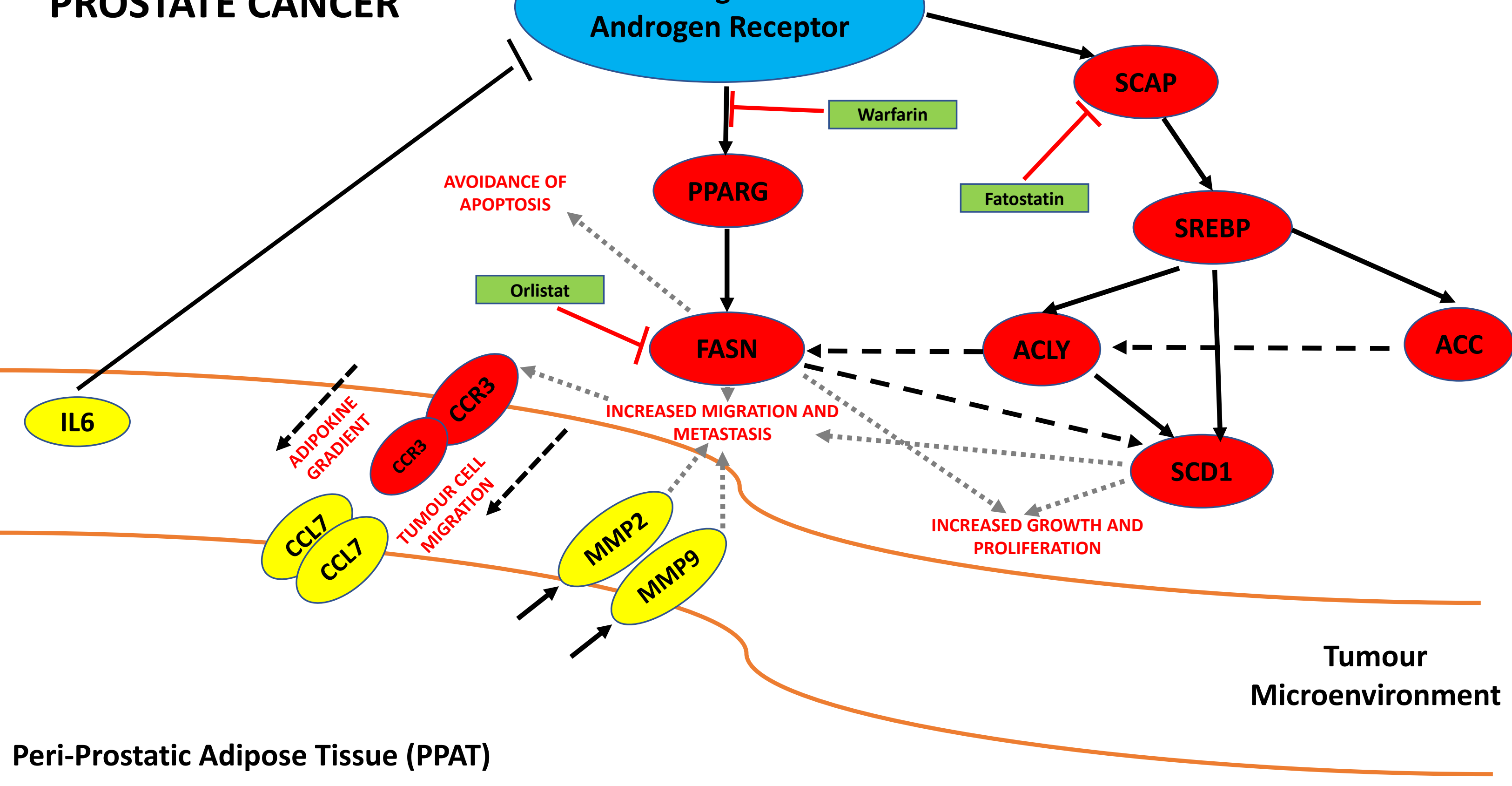

